\title{
Mediastinal Masses: Retrospective Single Center Based Study
}

Aram Baram* and Zirak Anwar Tayeb

Department of Thoracic and Cardiovascular Surgery, Faculty of Medical Sciences, School of Medicine, University of Sulaimani, Iraq

\section{Abstract}

Background: Mediastinal masses include a wide variety of tumors; could be congenital or acquired, cystic or solid, primary or secondary. They may arise from anterior, middle or posterior mediastinum. Neurogenic tumors are commonest childhood lesions; whereas lymphomas and thymic lesions are commonest in adults.

Methods: Retrospective analysis of all mediastinal masses presented to our unit from September $1^{\text {st }} 2007$ to July $1^{\text {st }} 2015$, all diagnostic modalities and and/or treatment by different surgical approaches are reviewed.

Results: Eighty-five patients with mediastinal masses in different age groups and both genders were studied There were 46 males and 39 females. Fifty-nine patients had anterior mediastinal masses, 13 patients had mediastinal lymphadenopathy and 14 patients had posterior mediastinal masses. Lymphoma was the commonest pathology $(32.94 \%)$ followed by thymic diseases $(24.7 \%)$, germ cell tumors $(11.76 \%)$ and neurogenic tumors $(10.59 \%)$. From 17 patients in pediatric age group lymphoma was the commonest pathology $(35.3 \%)$ followed by neurogenic tumors $(29.4 \%)$.

Conclusions: Mediastinal masses should be managed by a multidisciplinary team. Mediastinal Hydatid cyst in our locality is not uncommon disease. In mediastinal masses the role of surgery could be only diagnostic as in lymphoma cases thence we should be least invasive.

Keywords: Mediastinal masses; Lymphoma; Chamberlain; Thymectomy

\section{Introduction}

Mediastinal masses include a wide variety of tumors which are still a great challenge for thoracic surgeons, both about diagnosis and management [1]. They may be congenital or acquired, also can be primary or secondary. Mediastinal tumors represent $3 \%$ of all tumors seen within the chest [2]. Among these lesions, the most common histological types are lymphomas, thymomas and germ cell tumors [1]. The location and composition of a mass is critical to narrowing the differential diagnosis $[3,4]$. Anterior mediastinal tumors account for $50 \%$ of all mediastinal masses, including thymoma, teratoma, thyroid disease and lymphoma [5]. Masses of the middle mediastinum are typically congenital cysts while those arising in the posterior mediastinum are often neurogenic tumors [3].

Respiratory symptoms like cough, stridor, and wheezing are present in more than $60 \%$ of patients on presentation. A significant subset of patients will present with respiratory failure, superior vena cava (SVC)

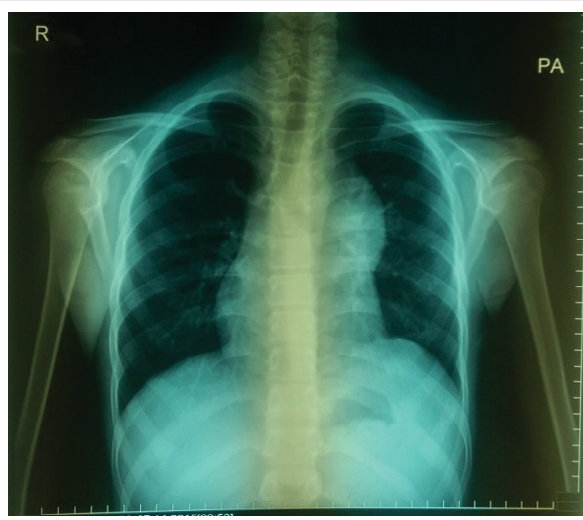

Figure 1: Postero-lateral chest radiograph of a 15 years old male with anterior mediastinal mass. syndrome, or other immediately life-threatening complaints [6]. Although nuclear scans and biochemical studies can be used to further characterize a lesion, tissue diagnosis is almost always required [3].

\section{Patients and Methods}

Most of the patients included in this research were presented with one symptom or more from shortness of breath, cough, chest pain, SVC syndrome and myasthenic symptoms for whom a mediastinal mass or lymphadenopathy found during the work up, others were included after a mediastinal mass found accidentally during work up for reasons other than mentioned symptoms.

Diagnostic workup for all patients included clinical examination, full haematological and biochemical investigations. Postero-anterior (Figure 1) and lateral chest radiographs, chest CT-scan with intravenous contrast (Figure 2), few patients sent for MRI of the dorsal spine (Figure 3) for assessment of spinal extension of posterior mediastinal masses. Patients with mediastinal lymphadenopathy sent for PET-scan for follow up and evaluation of the residual tumor tissue.

\section{Data entry and analysis}

The data was entered a Microsoft Excel Spreadsheet, after data cleaning; the data was transported into SPSS (Statistical Package for the Social Sciences-version 20) package software program for statistical analysis.

*Corresponding author: Baram A, Department of Thoracic and Cardiovascular Surgery, Faculty of Medical Sciences, School of Medicine, University of Sulaimani, François Mitterrand Street, Sulaymaniyah 46001 Iraq, Tel: +9647701511478; E-mail: aram.baramm@gmail.com, aram.baram@unvisul.edu.iq

Received August 12, 2016; Accepted October 27, 2016; Published October 29, 2016

Citation: Baram A, Tayeb ZA (2016) Mediastinal Masses: Retrospective Single Center Based Study. J Cancer Sci Ther 8: 252-256. doi: 10.4172/19485956.1000422

Copyright: $\odot 2016$ Baram A, et al. This is an open-access article distributed under the terms of the Creative Commons Attribution License, which permits unrestricted use, distribution, and reproduction in any medium, provided the original author and source are credited. 
Citation: Baram A, Tayeb ZA (2016) Mediastinal Masses: Retrospective Single Center Based Study. J Cancer Sci Ther 8: 252-256. doi: 10.4172/19485956.1000422

\section{Results}

\section{Age, gender and mediastinal mass location}

From September $1^{\text {st }} 2007$ to July $1^{\text {st }} 2015,85$ patients with mediastinal masses in different age groups and in both genders retrospectively studied and analyzed following diagnosis and/or treatment by different surgical approaches. Total of 85 patients 46 males and 39 females included in this study. Their age ranged from 4 to 75 year, with mean age of 35 years (Figure 4 ).

Pediatric age group constituted 17 (20\%) patients in this study, 12 males and 5 females, 9 (52.94\%) of them had anterior mediastinal mass, $3(17.65 \%)$ with middle mediastinal lymphadenopathy and $5(29.41 \%)$ with posterior mediastinal mass.

\section{Presentation}

From the 85 patients who are included in this study; dyspneoa

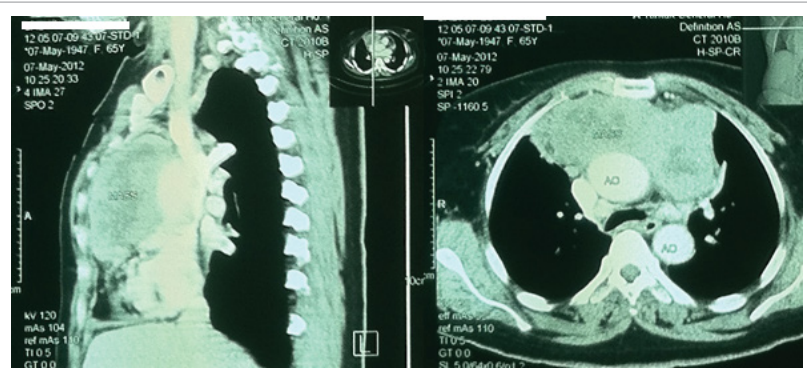

Figure 2: Chest CT-scan of a 65 years old female showing anterior mediastinal mass.

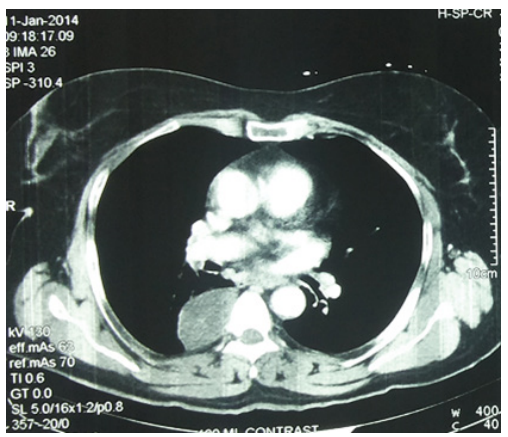

Figure 3: Chest CT-scan of a 60 years old female showing posterior mediastinal mass.

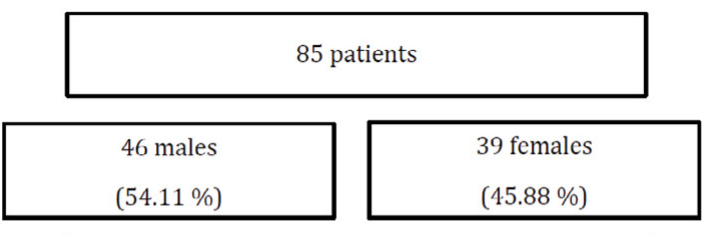

Age ( 4 months -75 years)

Mean 35 years, Median 31 years

\begin{tabular}{|c|c|c|}
\hline Anterior Mediastinal Mass & Middle Mediastinal Mass & Posterior Mediastinal Mass \\
58 cases $(68.24 \%)$ & 13 cases $(15.29 \%)$ & 14 cases $(16.47 \%)$ \\
$33(56.9 \%)$ males & $8(61.54 \%)$ males & $5(35.71 \%)$ males \\
$25(43.1 \%)$ females & $5(38.46 \%)$ females & $9(64.29 \%)$ females \\
\hline
\end{tabular}

Figure 4: Percentage of mediastinal masses in relation to age, gender and mediastinal location.

\begin{tabular}{|c|c|c|c|c|}
\hline & Symptom & Male & Female & Total \\
\hline & Dyspnea & 11 & 9 & $20(34.48 \%)$ \\
\hline & Myasthenic symptoms & 10 & 6 & 16 (27.59\%) \\
\hline \multirow{2}{*}{ 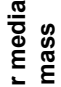 } & Chest pain & 7 & 4 & $11(18.96 \%)$ \\
\hline & Accidental finding & 2 & 2 & $4(6.9 \%)$ \\
\hline \multirow{3}{*}{ 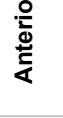 } & SVC syndrome & 1 & 2 & $3(5.17 \%)$ \\
\hline & Cough & 1 & 1 & $2(3.45 \%)$ \\
\hline & Painless cervical LAP & 1 & 1 & $2(3.45 \%)$ \\
\hline \multicolumn{2}{|c|}{ Total number of patients } & $33(56.9 \%)$ & 25 (43.1\%) & 58 \\
\hline
\end{tabular}

Table 1: Frequency and percentage of symptoms in relation to gender in anterio mediastinal masses.

\begin{tabular}{|c|c|c|c|c|}
\hline \multirow{4}{*}{ 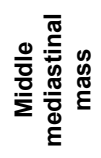 } & Symptom & Male & Female & Total \\
\hline & Dyspnea & 5 & 2 & $7(53.85 \%)$ \\
\hline & Cough & 2 & 3 & $5(38.46 \%)$ \\
\hline & Painless cervical LAP & 1 & 0 & $1(7.69 \%)$ \\
\hline \multicolumn{2}{|c|}{ Total number of patients } & $8(61.54 \%)$ & $5(38.46 \%)$ & 13 \\
\hline
\end{tabular}

Table 2: Frequency and percentage of symptoms in relation to gender in middle mediastinal masses.

\begin{tabular}{|c|c|c|c|c|}
\hline \multirow{6}{*}{ 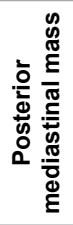 } & Symptom & Male & Female & Total \\
\hline & Dyspnea & 3 & 3 & $6(42.86 \%)$ \\
\hline & Accidental finding & 1 & 3 & $4(28.57 \%)$ \\
\hline & Paraplegia & 0 & 2 & $2(14.29 \%)$ \\
\hline & Cough & 1 & 0 & $1(7.14 \%)$ \\
\hline & Chest pain & 0 & 1 & $1(7.14 \%)$ \\
\hline \multicolumn{2}{|c|}{ Total number of patients } & $5(35.72 \%)$ & $9(64.28 \%)$ & 14 \\
\hline
\end{tabular}

Table 3: Frequency and percentage of symptoms in relation to gender in posterior mediastinal masses.

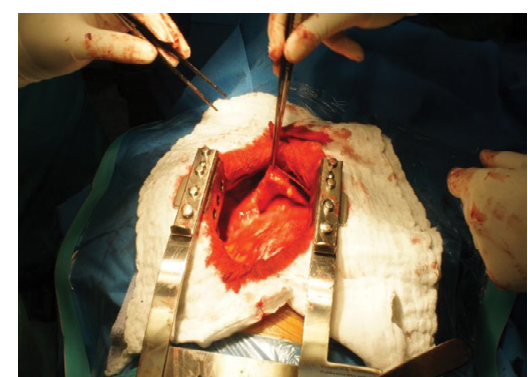

Figure 5: Median sternotomy and radical thymectomy for a 55-year-old male with myasthenia gravis.

alone was the main presenting symptom in 33 (38.82\%) patients, followed by chest pain in $12(14.12 \%)$ and myasthenic symptoms in 16 (18.83\%) patients, while $8(9.41 \%)$ patients had cough, SVC syndrome was presenting symptom in 3 (3.53\%) patients and painless cervical lymphadenopathy in 3 (3.53\%) patients. Progressive para-paresis and paraplegia was the main presenting symptom in $2(2.35 \%)$ patients. In the remaining $8(9.41 \%)$ patients a mediastinal mass found accidentally (Tables 1-3).

\section{Surgical approaches used to treat the lesions}
A- Median sternotomy (Figure 5)
B- Thoracotomy (Figure 6)
C- Anterior mediastinotomy (Chamberlain's operation) (Figure 7)
D- Cervical lymph node biopsy
E- Bone marrow biopsy 
Citation: Baram A, Tayeb ZA (2016) Mediastinal Masses: Retrospective Single Center Based Study. J Cancer Sci Ther 8: 252-256. doi: 10.4172/19485956.1000422

\section{Procedures and approaches}

From 85 operations performed there were 39 (45.88\%) total excisions done Debulking surgery done for $1(1.18 \%)$ large anterior mediastinal mass and $1(1.18 \%)$ patient with posterior mediastinal meningocele underwent operation for covering the meningocele with a pleural flap.

A total of 25 (29.41\%) incisional biopsies taken, 11 (12.94\%) mediastinal lymph node sampling, another 7 (8.23\%) patients underwent cervical lymph node biopsy taking and 1 (1.18\%) patient underwent bone marrow biopsy taking (Table 4).

\section{Pathology}

Total of 28 (32.94\%) patients diagnosed as lymphomas, with age range of 4-72 years, median 29 years and mean age 29.14 years; from these patients 15 (53.57\%) patients had Hodgkin's disease, 11 (39.29\%) patients with non-Hodgkin lymphoma and 2 (7.14\%) other patients with B cell lymphoma (Table 5).

Total of 22 patients with mediastinal lymphoma had anterior mediastinal mass and the other 6 patients had middle mediastinal lymphadenopathy. Lymphoma was present in $6(35.3 \%)$ patients in pediatric age group, all were male patients, 4 of them had anterior mediastinum involved and in 2 patients' middle mediastinum was involved, Hodgkin's disease was present in 5 of them and non-Hodgkin lymphoma in 1 patient.

Thymus gland related diseases presented in 21 (24.7\%) patients 11 males and 10 females; from these $12(57.15 \%)$ patients aged $48-75$ years with mean age 59.9 years had thymomas, 6 of them had benign thymoma and the other 6 patients had malignant thymoma, another $6(28.57 \%)$ patients had normal thymus tissue on histopathology, $2(9.52 \%)$ patients had thymic cyst and 1 (4.76\%) patient had thymolipoma. There were $3(17.65 \%)$ patients in pediatric age group with juvenile myasthenia gravis; all of them had normal thymic tissue on histopathology (Table 6).

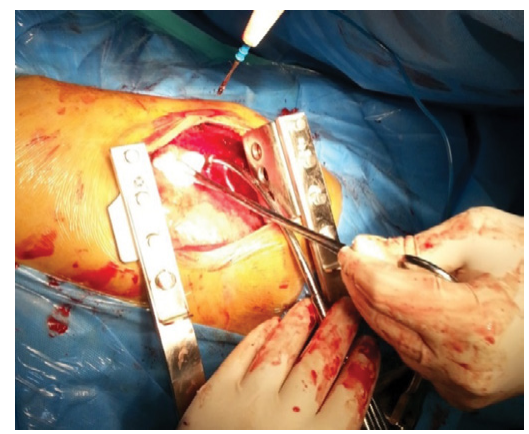

Figure 6: Left postero-lateral thoracotomy for a 29 years old male with posterior mediastinal mass.

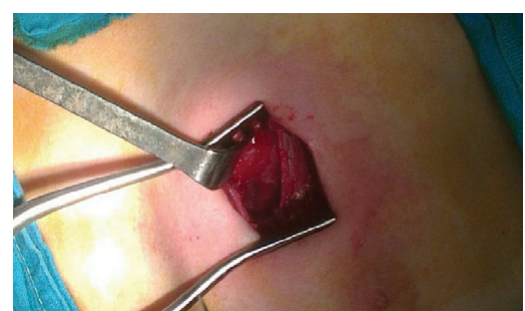

Figure 7: Left anterior mediastinotomy for a 22 years old male with anterior mediastinal mass.

\begin{tabular}{|c|c|c|c|c|c|}
\hline Approach & Procedure & Male & Female & Subtotal & Total \\
\hline \multirow{4}{*}{$\begin{array}{l}\text { Median } \\
\text { Sternotomy }\end{array}$} & Radical Thymectomy & 10 & 8 & 18 & \multirow{4}{*}{$\begin{array}{c}28 \\
(32.94 \%)\end{array}$} \\
\hline & $\begin{array}{l}\text { Resection of anterior } \\
\text { mediastinal mass }\end{array}$ & 5 & 3 & 8 & \\
\hline & Thyroidectomy & 0 & 1 & 1 & \\
\hline & Debulking surgery & 1 & 0 & 1 & \\
\hline \multirow{5}{*}{ Thoracotomy } & Mediastinal LN biopsy & 7 & 4 & 11 & \multirow{5}{*}{$\begin{array}{c}25 \\
(29.41 \%)\end{array}$} \\
\hline & $\begin{array}{l}\text { Posterior mediastinal } \\
\text { mass resection }\end{array}$ & 3 & 6 & 9 & \\
\hline & $\begin{array}{l}\text { Posterior mediastinal } \\
\text { hydatid cyst removal }\end{array}$ & 1 & 1 & 2 & \\
\hline & $\begin{array}{l}\text { Posterior mediastinal } \\
\text { mass incisional biopsy }\end{array}$ & 1 & 1 & 2 & \\
\hline & mediastinal meningocele & 0 & 1 & 1 & \\
\hline $\begin{array}{c}\text { Anterior } \\
\text { Mediastinotomy }\end{array}$ & $\begin{array}{l}\text { Anterior mediastinal mass } \\
\text { incisional biopsy taking }\end{array}$ & 15 & 8 & 23 & $\begin{array}{c}23 \\
(27.06 \%)\end{array}$ \\
\hline \multirow{2}{*}{ Cervical incision } & Cervical LN biopsy & 2 & 5 & 7 & \multirow{2}{*}{$8(9.41 \%)$} \\
\hline & Thymectomy & 1 & 0 & 1 & \\
\hline $\begin{array}{l}\text { Core needle } \\
\text { biopsy }\end{array}$ & Bone marrow biopsy & 0 & 1 & 1 & $1(1.18 \%)$ \\
\hline \multicolumn{2}{|c|}{ Total number of patients } & 46 & 39 & \multicolumn{2}{|c|}{85} \\
\hline
\end{tabular}

Table 4: Procedures and approaches performed in relation to gender.

\begin{tabular}{|c|c|c|c|}
\hline Subtype of lymphoma & Male & Female & Total \\
\hline Hodgkin's disease & 10 & 5 & $15(53.57 \%)$ \\
\hline Non-Hodgkin lymphoma & 7 & 4 & $11(39.29 \%)$ \\
\hline B-cell lymphoma & 1 & 1 & $2(7.14 \%)$ \\
\hline Total number of patients & $18(64.29 \%)$ & $10(35.71 \%)$ & 28 \\
\hline
\end{tabular}

Table 5: Frequency and percentage of lymphoma and its subtypes.

\begin{tabular}{|c|c|c|c|c|}
\hline \multicolumn{2}{|c|}{ Thymic disease } & Male & Female & Total \\
\hline \multirow{2}{*}{ Thymoma } & Benign & 3 & 3 & $6(28.57 \%)$ \\
\cline { 2 - 5 } & Malignant & 3 & 3 & $6(28.57 \%)$ \\
\hline \multicolumn{2}{|r|}{ Normal thymus } & 4 & 2 & $6(28.57 \%)$ \\
\hline \multicolumn{2}{|r|}{ Thymic cyst } & 1 & 1 & $2(9.52 \%)$ \\
\hline \multicolumn{2}{|r|}{ Thymolipoma } & 0 & 1 & $1(4.76 \%)$ \\
\hline Total number of patients & $11(52.38 \%)$ & $10(47.62 \%)$ & 21 \\
\hline
\end{tabular}

Table 6: Frequency and percentage of thymus related diseases.

\begin{tabular}{|c|c|c|c|}
\hline Germ cell tumor & Male & Female & Total \\
\hline Malignant Germ cell tumor & 6 & 1 & $7(70 \%)$ \\
\hline Benign teratoma & 2 & 1 & $3(30 \%)$ \\
\hline Total number of patients & $8(80 \%)$ & $2(20 \%)$ & 10 \\
\hline
\end{tabular}

Table 7: Frequency and percentage of germ cell tumors.

Germ cell tumors were present in $10(11.76 \%)$ patients, aged 11 59 years, median 24.4 years and mean age 30 years. These included 3 (30\%) benign teratomas and $7(70 \%)$ malignant germ cell tumors. Two of the patients were in pediatric age group, both were male, they had malignant germ cell tumors (Table 7).

Total of 9 (10.59\%) patients presented with neurogenic tumors, they aged between 4 months to 58 years, median 3 years and mean age 19.9 years. From these; $6(66.66 \%)$ patients had malignant and the other $3(33.33 \%)$ patients had benign neurogenic tumors. There were 5 $(55.55 \%)$ patients in pediatric age group with neurogenic tumors, all of them had neuroblastoma (Table 8).

Tuberculous lymphadenopathy was present in $6(7.06 \%)$ patients, 3 males and 3 females, aged 16-55 years, median 38 years and mean age 37 years. Sarcoidosis was present in $3(3.53 \%)$ female patients, aged 25 53 years, median 43 years and mean age 40.33 years.

There were $2(2.35 \%)$ patients with hydatid cyst in posterior 
mediastinum, one male 57 years and one female 40 years, median and mean age 48.5 years.

Another 2 (2.35\%) female patients had solitary fibrous tumor in posterior mediastinum, their age was 24 and 65 years, median and mean age 44.5 years.

Only 1 (1.18\%) female patient had leukemia, T-cell type, she was 38 years' age, one $(1.18 \%)$ female patient had substernal goitre, she was 45 years' age and another $1(1.18 \%)$ patient also female, aged 52 years, had anterior spinal meningocele in posterior mediastinum.

Lastly there was one (1.18\%) male patient age 64 years with anterior mediastinal secondary metastatic adenocarcinoma (Table 9).

\section{Discussion}

Mediastinal tumors are uncommon and represent 3\% of all thoracic tumors [2,3]. Mediastinal masses can be benign or malignant in behavior, solid or cystic in nature and they can involve every compartment of the mediastinum. The location and composition of a mass is critical to narrowing the spectrum of the differential diagnosis. However, types of mediastinal tumors are usually associated with the patient's age $[3,7]$.

In our study, 85 patients of mediastinal mass that confirmed by imaging and surgical biopsy, from all age groups with mean age of 35 years and there was male predominance. The age range and mean ages are very close to a study by Biswajit Dubashi, et al. [8] and another study by Karki and Chalise [9].

Mediastinal mass is symptomatic in $60 \%$ of the patients in the literature [10]. About $93 \%$ of the patients in this study were symptomatic; a study by Davis, et al. found that $85 \%$ of the patients with malignancy were symptomatic; and only $46 \%$ of the patients with benign tumors had identifiable complaints [10]. Although many of these masses have similar imaging appearances, clinical history, anatomical position and certain details seen at CT and MRI imaging allow correct diagnosis in many cases [5].

\begin{tabular}{|c|c|c|c|c|}
\hline \multicolumn{2}{|c|}{ Neurogenic tumor } & Male & Female & Total \\
\hline \multicolumn{2}{|c|}{ Malignant neuroblastoma } & 1 & 4 & $5(55.55 \%)$ \\
\hline \multirow{2}{*}{ Schwannoma } & Benign & 2 & 0 & $2(22.22 \%)$ \\
\hline & Malignant & 0 & 1 & $1(11.11 \%)$ \\
\hline \multicolumn{2}{|c|}{ Benign neurofibroma } & 1 & 0 & $1(11.11 \%)$ \\
\hline \multicolumn{2}{|c|}{ Total number of patients } & $4(44.44 \%)$ & $5(55.55 \%)$ & 9 \\
\hline
\end{tabular}

Table 8: Frequency and percentage of neurogenic tumors.

\begin{tabular}{|c|c|c|c|}
\hline Disease & Male & Female & Total \\
\hline Lymphoma & 18 & 10 & $28(32.94 \%)$ \\
\hline Thymic diseases & 11 & 10 & $21(24.7 \%)$ \\
\hline Germ cell tumors & 8 & 2 & $10(11.76 \%)$ \\
\hline Neurogenic tumors & 4 & 5 & $9(10.59 \%)$ \\
\hline Tuberculous lymphadenopathy & 3 & 3 & $6(7.06 \%)$ \\
\hline Sarcoidosis & 0 & 3 & $3(3.53 \%)$ \\
\hline Hydatid cyst & 1 & 1 & $2(2.35 \%)$ \\
\hline Solitary fibrous tumor & 0 & 2 & $2(2.35 \%)$ \\
\hline Leukemia & 0 & 1 & $1(1.18 \%)$ \\
\hline Substernal goiter & 0 & 1 & $1(1.18 \%)$ \\
\hline Meningocele & 0 & 1 & $1(1.18 \%)$ \\
\hline Secondary metastatic & 1 & 0 & $1(1.18 \%)$ \\
\hline adenocarcinoma & $46(54.12 \%)$ & $39(45.88 \%)$ & 85 \\
\hline Total number of patients & & & \\
\hline
\end{tabular}

Table 9: Frequency and percentage of mediastinal diseases.
The diagnosis of mediastinal disorders may be approached in 2 phases: Non-invasive imaging techniques and invasive procedures for tissue sampling [8]. Although nuclear scans and biochemical studies can be used to further characterize a lesion [3]. Nevertheless, surgical biopsy remains the most important tool in diagnosing these disorders [11]. To achieve the pathology and the type of mediastinal mass, different approaches have been adopted based on the location of the mass [7].

Some patients included in this study diagnosed through blood samples, bone marrow biopsy and/or incisional biopsy taking to confirm diagnosis before starting definitive treatment, some others underwent total resection of the mass with sending for excisional biopsy to determine final diagnosis and assessment for need of further treatment and follow up.

Using methods of ultrasound and CT guided FNA were avoided because these procedures are operator dependent and the amount of tissue that is obtained for biopsy is not sufficient all the time for examination. Adler, et al in a study of 84 patients underwent FNAC for mediastinal masses found $8.33 \%$ of unspecific samples and $11.9 \%$ of unrepresentative samples [12]. In this study Lymphoma formed about $33 \%$ of the mediastinal diseases, about $38 \%$ of anterior mediastinal masses and about $46 \%$ of middle mediastinal masses, where as a study by Sabiston, et al. found that $16 \%$ of mediastinal tumors were lymphomas [13]. Dutta et al. found that lymphomas were representing only $8 \%$ of mediastinal tumors from which $12 \%$ were anterior mediastinal masses and $14.3 \%$ middle mediastinal masses [14]. In the current study lymphoma was the commonest cause of anterior and middle mediastinal masses in the pediatric age group $44.44 \%$ and $66.66 \%$ respectively.

In this study thymomas were contributing to form $20.7 \%$ of anterior mediastinal pathology which is comparable to the currently published literature [3]. Thymic cysts presented in $2.35 \%$ of patients in the current study, Takeda, et al showed $3.72 \%$ in a study [15]. Normal thymic tissue was found in $28.5 \%$ of patients with myasthenia gravis in this study, Pirronti et al. found that about $17.3 \%$ of patients with myasthenia had normal thymic tissue in his study [16]. Thymolipoma was representing $4.8 \%$ of thymic masses in this study, according to the literature it represents about $2 \%$ to $9 \%$ of thymic tumors [17].

Mediastinal germ cell tumors are rare and representing approximately $15 \%$ of mediastinal primitive tumors [18], in our study they represent $11.76 \%$ from these $70 \%$ were malignant, leaving benign teratoma to represent only $30 \%$ of the patients; however, generally benign teratomas are most common germ cell tumors of the mediastinum [19].

Neurogenic tumors constituted $69.2 \%$ of posterior mediastinal tumors, neuroblastoma was the commonest. These results are like those of a study by Abdel Rahman, et al. [20]. In this study, tuberculous lymphadenopathy was present in $7.06 \%$, Wychulis, et al. found it present in $3.4 \%$ of patients in a study and Cohen, et al. found $22.9 \%$ [14]. Sarcoidosis was found in $3.5 \%$ of patients in this study, taking $23 \%$ of middle mediastinal pathologies, in the literature it is mentioned that sarcoidosis is found with varying frequency in virtually every country in the world [21]. Primary mediastinal hydatid cyst was representing about $2.35 \%$ of the mediastinal masses and about $14.3 \%$ of posterior mediastinum in this study, in English language literature mediastinal hydatid cysts are rarely reported [22].

Solitary fibrous tumor was representing about $2.35 \%$ of the mediastinal masses in this study, it is mentioned in literature that it 
Citation: Baram A, Tayeb ZA (2016) Mediastinal Masses: Retrospective Single Center Based Study. J Cancer Sci Ther 8: 252-256. doi: 10.4172/19485956.1000422

represents less than $5 \%$ of all mediastinal masses [23]. Mediastinal thyroid tumors constitute about 5\% [14], while in this study it represented only $1.18 \%$ of the cases; the cause for this difference is not explained by our study. In current study, mediastinal meningocele also represented $1.18 \%$, in a study Takeda, et al. found $0.25 \%$ [15]. In various series of study on mediastinal masses, incidence of malignant lesions ranged from $25 \%$ to $49 \%$ [2], however; in this study, malignant diseases formed about $56.5 \%$ of the pathologies which represent no statistically significant finding. In comparison to another study by Akshatha Aroor, et al. this study included less secondary malignant diseases of mediastinum with $1.18 \%$ vs $8.75 \%$ [2].

\section{Conclusions}

Mediastinal masses should be managed by a multidisciplinary team because most of them need different adjuvant therapy. Anterior mediastinal masses are the commonest in our locality so we should pay more attention to any abnormality that is detected accidentally in a routine chest X-ray.

In the review of the international literature mediastinal hydatid cysts are rarely found to be the cause of the mass while in our locality it is not uncommon.

Lymphomas are very common cause of mediastinal masses, so we must be least invasive when dealing with any mediastinal mass because the role of surgery is mostly diagnostic in this disease.

\section{References}

1. Guillem P, Porte H, Copin MC, Chevallier D (1998) A case of giant chondrosarcoma of the cricoid cartilage presenting as a superior mediastinal tumour. Eur J Cardiothorac Surg 14: 520-522.

2. Aroor AR, Prakasha SR, Seshadri S, Teerthanath S, Raghuraj U (2014) A Study of Clinical Characteristics of Mediastinal Mass. J Clin Diagn Res 8: 77-80.

3. Duwe BV, Sterman DH, Musani Al (2005) Tumors of the mediastinum. Chest 128: 2893-2909.

4. Shields TW (2009) The Mediastinum, Its Compartments, and the Mediastinal Lymph Nodes. In: Shields TW, LoCicero J, Reed CE, Feins RH (Eds.) General thoracic surgery (7thedn), Wolters Kluwer/Lippincott Williams \& Wilkins, Philadelphia.

5. Juanpere S, Cañete N, Ortuño P, Martínez S, Sanchez G, et al. (2013) A diagnostic approach to the mediastinal masses. Insights Imaging 4: 29-52.

6. Kennebeck SS (2005) Tumors of the Mediastinum. Clin Ped Emerg Med 6: 156-164.
7. Bagheri R, Afghani R, Haghi SZ, Fattahi Masoum SH, Moghaddam SZ, et al (2015) Evaluation of 95 Cases with Mediastinal Tumors. J Cardiothorac Med 3: 249-253.

8. Kane GC, Almeida FA Jr (2007) Approach to Mediastinal Masses. Hospital physician pulmonary disease board review manual 12: 2-13.

9. Karki S, Chalise S (2011) Analysis of mediastinal lesions: a study of 27 cases. Journal of Pathology of Nepal 1: 114-117.

10. Dubashi B, Cyriac S, Tenali SG (2009) Clinicopathological analysis and outcome of primary mediastinal malignancies: a report of 91 cases from a single institute. Ann Thorac Med 4: 104-142.

11. Cirino LM, Milanez de Campos JR, Fernandez A, Samano MN, Fernandez PP et al. (2000) Diagnosis and treatment of mediastinal tumors by thoracoscopy. Chest 117: 1787-1792.

12. Adler OB, Rosenberger A, Peleg H (1983) Fine-Needle Aspiration Biopsy of Mediastinal Masses: Evaluation of 136 Experiences. AJR 140: 893-896.

13. Davis RD Jr, Oldham HN, Sabiston DC Jr. (1987) Primary cysts and neoplasms of the mediastinum: recent changes in clinical presentation, methods of diagnosis, management, and results. Ann Thorac Surg 44: 229-237.

14. Dutta P, Patel KKR, Choudhury PR (2014) Mediastinal Masses: A Radiological Study of 50 Cases. IJBR 5: 468-473.

15. Takeda S, Miyoshi S, Minami M, Ohta M, Masaoka A, et al. (2003) Clinica Spectrum of Mediastinal Cysts. Chest 124: 125-132.

16. Pirronti T, Rinaldi P, Batocchi AP, Evoli A, Di Schino C, et al. (2002) Thymic lesions and myasthenia gravis. Diagnosis based on mediastinal imaging and pathological findings. Acta Radiol 43: 380-384.

17. Gaerte SC, Meyer CA, Winer-Muram HT, Tarver RD, Conces DJ Jr. (2002) Fatcontaining lesions of the chest. Radiographics 22: S61-S78.

18. Bachh AA, Haq I, Gupta R, Boinapally RM, Sudhakar S (2010) Benign mediastinal teratoma with intrapulmonary extension presenting with trichoptysis. Respir Med CME 3: 189-191.

19. Romagnani E, Gallerani E, Cavalli F (2006) Mediastinal mature teratoma with an immature component-what about the treatment?. Ann Oncol 17: 1602-1604.

20. Abdel Rahman AR, Sedera MA, Mourad IA, Aziz SA, Saber TK, et al. (2005) Posterior Mediastinal Tumors: Outcome of Surgery. J Egypt Natl Canc Inst 17: $1-8$

21. Miller BH, Rosado-de-Christenson ML, McAdams HP, Fishback NF (1995) Thoracic sarcoidosis: Radiologic-Pathologic Correlation. Radio Graphics 15: 421-437.

22. Polat $P$, Kantarci M, Alper F, Suma S, Koruyucu MB, et al. (2003) Hydatid Disease from Head to Toe. RadioGraphics 23: 475-494.

23. Meroni S, Funicelli L, Rampinelli C, Galetta D, Bonello L, et al. (2012) Solitary fibrous tumours: unusual aspects of a rare disease. Hippokratia 16: 269-274. 